\title{
Optimization of Surface Roughness for EN 1010 Low Alloy Steel on WEDM Using Response Surface Methodology
}

\author{
Munish Giri ${ }^{1}$, Manjeet Bohat ${ }^{2}$, Ravinder Chaudhary ${ }^{3}$, Anish Taneja ${ }^{4}$ \\ ${ }^{1}$ Research Scholar, Department of Mechanical Engineering, UIET, KurukshetraUniversity Kurukshetra, India \\ ${ }^{2}$ Asst. Profes sor, Department of Mechanical Engineering, UIET, Kurukshetra University Kurukshetra, India \\ ${ }^{3}$ Asst. Profes sor, Department of Mechanical Engineering, UIET, Kurukshetra University Kurukshetra, India \\ ${ }^{4}$ Asst. Profess or, Department of Mechanical Engineering, SKIET, Kurukshetra, India
}

\begin{abstract}
The term steel is used for many different alloys of iron. All steels cover small amounts of carbon and manganese. There do exist many types of steels which are(among others) plain carbon steel, stainless steel, alloysteel and tool steel. Carbon steel is the most extensively used kind of steel. The properties of carbon steel depend mainly on the amount of carbon it contains. Maximum carbon steel has a carbon content ofless than $1 \%$. Carbon steel is made into an extensive range of products, including structural beams, car bodies. In fact, there are 3 types of plain carbon steel namely low carbon steel, medium carbon steel, high carbon steel. It is good to exact that plain carbon steel is a type of steel having a maximum carbon content of $1.5 \%$ along with small percentages of silica, Sulphur, phosphorus and manganese. EN 1010 is a lowest amount of carbonalloy steel alloy with carbon content of $0.10 \%$. Machineability of EN 1010 carbon steel is measured to be fairly good. EN 1010 is usually used for rivets and bolts, construction and automotive applications such as pans, nails and transmission cover. The objective of paper is to study the effect of process parameters namely pulse on time, pulse off time, peak current and servo voltage on surface roughness(SR).The effect of process parameters on productivity and accuracy facts is material dependent. To study parametric effect on Surface Roughness a Central Composite design approach of response surface methodology (RSM) is used to plan and study the experiments. The mathematical relationships between WEDM input process parameters and response parameter namely surface roughness is established to determine optimal values of surface roughness mathematically and graphically.The Analysis of variance (ANOVA) is performed to find statistically significant process parameters. Interaction effects of process parameters on surface roughness are analysed using statistical and graphical representations.
\end{abstract}

Keywords- ANOVA, CCD, EN 1010, RSM, Surface Roughness, Wire EDM.

\section{INTRODUCTION}

The objective of this paper is to analyse the effect of different input process parameters like pulse on time (Ton), pulse off time (Toff), peak current (Ip) and servo voltage $(\mathrm{Sv})$ of Wire EDM on output response namelysurface roughness using response surface methodology(RSM), in particular the central composite design (CCD). The mathematical models so produced have been analysed and optimized to give the values of process parameters producing the optimal values of the Surface Roughness

\section{LITERATURE REVIEW}

HoK. H et al. [1] (2004)reviewed the large array of research work done from inception of the EDM process to its development. It suggested on the Wire EDM research work involving optimization of the process parameters, influence of different factors affecting the productivity and machining performance. The paper also showed the adaptive monitor and control of process investigating the possibility of different control strategies to obtain the optimum machining conditions

Ramakrishnan R. and Karuna Moorthy L. [2] (2008) described the growth of Artificial Neural Network (ANN) models and the Multi Responseoptimization technique to envisage and select the best cutting parameters of Wire Electrical Discharge Machining (WEDM) process. To envisage the performance characteristics viz. Surface Roughness, Material Removal Rate Artificial Neural Network models were formed using the Back-Propagation algorithms. Inconel 718 was selected as the work material to conduct the experiments. Experiments were done as per the Taguchi's L9 Orthogonal Array. The responses were optimized using the Multi Response Signal-To-Noise (MRSN) ratio in addition to the Taguchi's parametric design approach 
Pa Jagannathan et al. [3] (2012) This paper studied of EN31 used material as a workpiece. It is done in Taguchi L27 orthogonal array (OA) by Design of experiments (DOE) table. In this paper a WEDM process rough machining gives lesser accuracy and finish machining gives fine surface finish, but it reduces the machining speed. Hence the result was obtained by improve the MRR and reduce the Ra as the objective, which was done by Taguchi method.

Noor khan et al. [4] (2013) investigation the parameters of wire electric discharge machining of high strength and low alloy (HSLA) steels has been carried out. HSLA steels provide greater resistance to atmospheric corrosion. The work has been done using Taguchi L9 orthogonal array. Each experiment was conducted under different parameters combinations of pulse on time, pulse off time and peak current. The machining parameter was optimized combination by using the ANOVA for determine the level of the machining parameters on micro-hardness. The study was used as Taguchi technique for minimum number of marks on the surface $\mathbf{S}$.

Sivanaga et al. [5] (2014) This work deals with the effect of thickness of the job on discharge current, cutting speed, spark gap/over cut, metal removal rate and surface roughness value of high carbon high chromium steel (HC$\mathrm{HCr}$ ). In this work a die steel cut by wire-electrical discharge machining (WEDM) was used. To obtain a good quality workpiece the machine was experimentally optimized. The mathematical relation developed for estimated thickness of workpiece for an output criterion.

Kumar Jitender and Rupesh [6] (2015) study that multi response optimization technique has been undertaken by using traditional method in finish cut WEDM. In this paper pure titanium used as a work material. The effect of process parameters on response variables i.e. MRR, surface roughness. Two different types of electrodes were used in this work to predict the MRR over a wide range of parameters. Result was obtained using ANOVA.

Abhijit Sahal and Himadri Majumder [7] (2016) this paper process capability study was performed for turning operation. Three process input like spindle speed, feed and depth of cut has been chosen for process capability study in plain turning operation by Taguchi's L27 orthogonal array. Process Capability Index was estimated for two machining characteristics frequency of tool vibration and average surface roughness. Single response optimization was affected for these two machining qualities to travel the input settings, which could optimize turning process ability. Optimum limit settings for frequency of tool vibration and average surface roughness were found to be spindle speed: $240 \mathrm{rpm}$, feed: 0.16 $\mathrm{mm} / \mathrm{rev}$, depth of cut $0.2 \mathrm{~mm}$ and spindle speed: $240 \mathrm{rpm}$, feed: $0.16 \mathrm{~mm} / \mathrm{rev}$, depth of cut: $0.1 \mathrm{~mm}$. respectively.

Kumar Sujeet Chaubey and Kumar Neelesh Jain[8] (2017) paper presents review of the past research work accepted out on manufacturing of micro spur and helical gears highlighting their material, specifications, type of manufacturing processes used, their capabilities and limitations. It exposes most of the past work has attentive on manufacturing of meso and micro spur gear using various micro-manufacturing processes which yield poor quality. The optimization of input parameters of the micro manufacturing processes distressing quality of the meso and micro gears. Based upon these exposures, it also categorizes the commands and possibility for future research in this significant area of micro-manufacturing.

\section{EXPERIMENT METHODOLOGY}

3.1 Machine tool

In this research work, SR is Output characteristics. This output characteristic is studied under varying conditions of input process parameters, which are namely pulse on time (Ton), pulse off time (Toff), peak current (Ip)and servo voltage $(\mathrm{Sv})$. The experiments were performed on Electronica Sprintcut $734 \mathrm{CNC}$ Wirecut machine as shown in figure 3.1. Electronica Sprintcut734 provides full freedom to operator in choosing the parameter values with in a wide range. A brass wire of $0.25 \mathrm{~mm}$ diameter is used as the cutting tool material. Deionized water is used as dielectric, which flush away metal particle from the workpiece. 


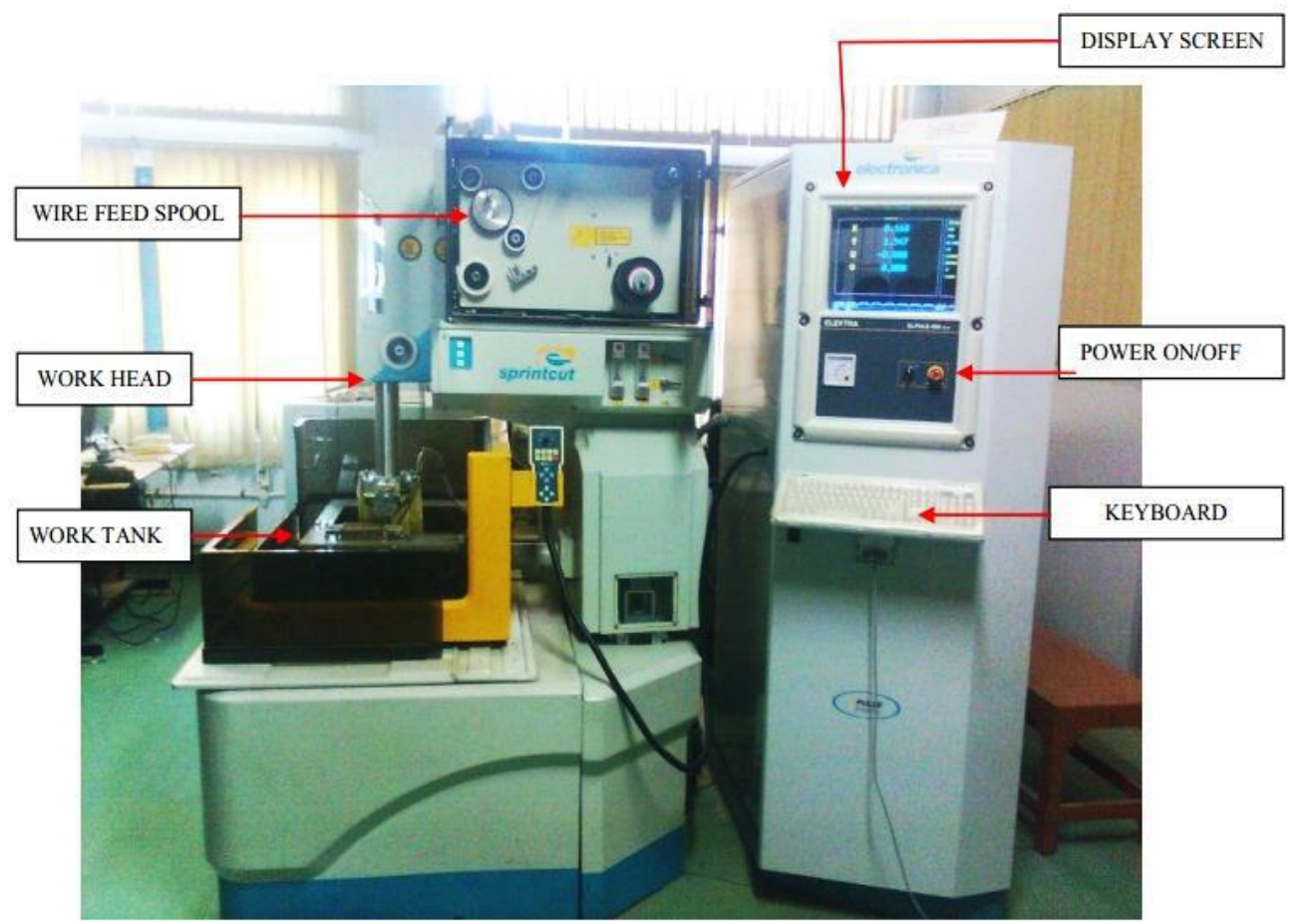

Fig.3.1: Electronica Sprintcut 734 CNC wire cut machine and its parts

\subsection{Material}

EN 1010 is a low-carbon steel alloy with $0.10 \%$ carbon content. It is known for its fairly low strength and low ductility; however, it can be quenched to increase strength. Machineability of EN 1010 carbon steel is measured to be equally good. EN 1010 is commonly used for cold headed fasteners, rivets and bolts, in addition to structural, construction and automotive applications such as fenders, pans, nails and transmission covers. Table 3.1 gives the chemical composition of the work material.

Table.3.1: Chemical composition of EN 1010

\begin{tabular}{|c|c|c|c|c|c|}
\hline Eement & C & Si & Mn & P & S \\
\hline \% age by Weight & 0.1144 & 0.0908 & 0.3843 & 0.04255 & 0.02170 \\
\hline
\end{tabular}

The work material used is in rectangular form of dimensions as given below. Figure 3.2 shows the workpiece material used for experiment purpose.

Length $=200 \mathrm{~mm}$, Breadth $=100 \mathrm{~mm}$, Height $=10 \mathrm{~mm}$

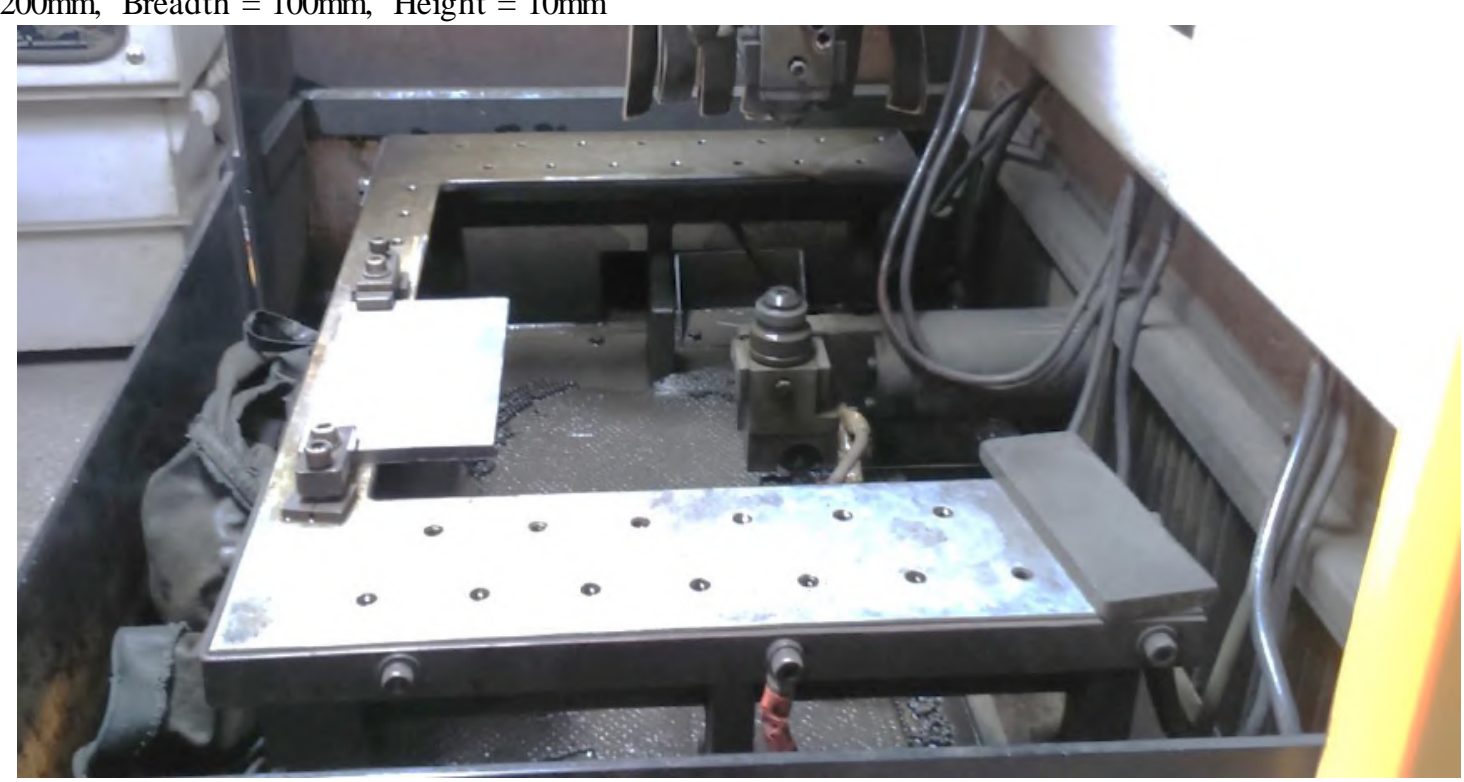

Fig.3.2: EN 1010 workpiece material 
3.2 RSM and Design of Experiment

Response surface methodology is a collection of the statistical and mathematical methods which are useful for the modelling and optimization of engineering science problems. Response surface methodology discovers the relationships between controllable input parameters and obtained outputs. There are in total 21 experiments carried out according to design of experiments. The average values of SR $(\mu \mathrm{m})$ are shown in Table 3.2.

Table.3.2: Design of Experiment and SR

\begin{tabular}{|c|c|c|c|c|c|}
\hline Run & Ton & Toff & Ip & $\mathbf{S v}$ & SR \\
\hline 1 & 130 & 50 & 80 & 10 & 2.69 \\
\hline 2 & 120 & 30 & 155 & 30 & 2.68 \\
\hline 3 & 110 & 40 & 80 & 10 & 2.49 \\
\hline 4 & 130 & 50 & 230 & 10 & 2.98 \\
\hline 5 & 120 & 40 & 155 & 30 & 2.7 \\
\hline 6 & 120 & 50 & 155 & 30 & 2.60 \\
\hline 7 & 120 & 40 & 230 & 30 & 2.99 \\
\hline 8 & 130 & 30 & 80 & 50 & 2.80 \\
\hline 9 & 120 & 40 & 90 & 30 & 2.50 \\
\hline 10 & 130 & 40 & 155 & 30 & 2.8 \\
\hline 11 & 110 & 30 & 80 & 50 & 2.4 \\
\hline 12 & 120 & 30 & 155 & 50 & 2.62 \\
\hline 13 & 120 & 40 & 155 & 30 & 2.7 \\
\hline 14 & 110 & 40 & 155 & 30 & 2.58 \\
\hline 15 & 120 & 40 & 155 & 10 & 2.61 \\
\hline 16 & 120 & 40 & 155 & 30 & 2.78 \\
\hline 17 & 120 & 40 & 155 & 30 & 2.76 \\
\hline 18 & 110 & 40 & 230 & 10 & 2.59 \\
\hline 19 & 110 & 50 & 230 & 50 & 2.56 \\
\hline 20 & 130 & 30 & 230 & 50 & 2.70 \\
\hline 21 & 120 & 40 & 155 & 30 & $2 . .79$ \\
\hline
\end{tabular}

\section{RESULT AND DISCUSSIONS}

4.1 Analysis of Surface Roughness

According to fit summary obtained from analysis, it is found that the quadratic model is statistically significant for SR. The results of quadratic model for SR in the form of ANOVA are presented in Table 4.1.If $F$ value is more corresponding, $\mathrm{p}$ value must be less and corresponding resulting in a more significant coefficient. Non-significant terms are removed by the backward elimination for fitting of SR in the model. Alpha out value is taken as 0.05 (i.e.,95\% confidence level). It is found from the Table 4.1 that $F$ value of model is 12.35 and related $p$ value is $<0.0001$ results in a significant model. The lack of fit is a measure of failure of model to represent data in experimental field at which the points are not included in regression differences in model that cannot be accounted for by the random error. If there is the significant lack of fit, as indicated by the low probability value, response predictor is discarded. Lack of fit is non-significant and its value is 2.55.From Table 4.1 it is found that $\mathrm{R}^{2}$ of model is 0.9851 , which is very close to 1 . It means that $98.51 \%$ variation can be explained by the model and only $0.02 \%$ of the total variation cannot be explained, which is the indication of good accuracy. The predicted $\mathrm{R}^{2}$ is in theological concurrence with adjusted $\mathrm{R}^{2}$ of 0.9071. Figure4.1 shows normal probability plot of residuals for SR. Most of residuals are found around straight line, which means that the errors are normally distributed. Adequate precision compares significant factors to non-significant factors, i.e., signal to noise ratio. According to results obtained from software, ratio greater than 4 is desirable. In this, adequate precision is 15.724 So, signal to noise ratio is significant. By applying multiple regression analysis on experimental data, empirical relation in terms of actual factors obtained as follows, equation 4.1 
$\mathrm{SR}=-1.8576415+0.0317377 *$ Ton+0.061463*Toff-

$0.015994 * \mathrm{Ip}+0.759481 * \mathrm{~Sv}-0.00085794 * \mathrm{Ton}^{2}-$

$0.0010708 * \operatorname{Toff}^{2}+0.000839373 * \mathrm{Ip}^{2}-$
$0.0006304 * \mathrm{~Sv}^{2} 0.0001514 * \mathrm{Ton} * \mathrm{Ip}+$

$0.0004403^{*}$ Toff*Ip- 0.0017092 To ff*Sv +0.0001524

*Ip*Sv

Table.4.1: ANOVA of Response surface for surface roughness

\begin{tabular}{|c|c|c|c|c|c|c|}
\hline \multicolumn{7}{|c|}{$\begin{array}{c}\text { ANOVA for Response Surface Reduced Quadratic Model } \\
\text { Analysis of variance table [Partial sum of squares] }\end{array}$} \\
\hline Source & $\begin{array}{l}\text { Sum of } \\
\text { Comome }\end{array}$ & DF & $\begin{array}{c}\text { Mean } \\
\text { comomn }\end{array}$ & $\begin{array}{c}\text { F } \\
\text { Volwo }\end{array}$ & p-value & \\
\hline Model & 0.400373 & 10 & 0.04004 & 12.354 & 0.0002 & Significant \\
\hline A-Ton & 0.0277652 & 1 & 0.02777 & 8.5674 & 0.0151 & \\
\hline B-Toff & 0.0145212 & 1 & 0.01452 & 4.4807 & 0.0604 & \\
\hline C-Ip & 0.1523956 & 1 & 0.1524 & 47.024 & $<0.0001$ & \\
\hline D-Sv & 0.0411476 & 1 & 0.04115 & 12.697 & 0.0052 & \\
\hline $\mathrm{AC}$ & 0.0439432 & 1 & 0.04394 & 13.559 & 0.0042 & \\
\hline $\mathrm{BC}$ & 0.0859131 & 1 & 0.08591 & 26.51 & 0.0004 & \\
\hline $\mathrm{BD}$ & 0.0599051 & 1 & 0.05991 & 18.485 & 0.0016 & \\
\hline $\mathrm{CD}$ & 0.0523508 & 1 & 0.05235 & 16.154 & 0.0024 & \\
\hline $\mathrm{A}^{2}$ & 0.086463 & 1 & 0.086463 & 648.0429 & $<0.0001$ & \\
\hline $\mathrm{B}^{2}$ & 0.0205861 & 1 & 0.02059 & 6.3522 & 0.0304 & \\
\hline $\mathrm{C}^{2}$ & 0.002992 & 1 & 0.002992 & 22.42587 & 0.0021 & \\
\hline $\mathrm{D}^{2}$ & 0.0710337 & 1 & 0.07103 & 21.919 & 0.0009 & \\
\hline Residual & 0.032408 & 10 & 0.00324 & & & \\
\hline Lack of Fit & 0.025688 & 6 & 0.00428 & 2.5484 & 0.1922 & $\begin{array}{l}\text { Not } \\
\text { significant }\end{array}$ \\
\hline Pure Error & 0.00672 & 4 & 0.00168 & & & \\
\hline Cor Total & 0.432781 & 20 & & & & \\
\hline Std. Dev. & 0.056928 & & & -Squared & & 0.9251 \\
\hline Mean & 2.682381 & & & R-Squar & & 0.8502 \\
\hline C.V. $\%$ & 2.1222938 & & & R-Squar & & 0.9071 \\
\hline PRESS & 0.8124115 & & & q Precisi & & 15.724 \\
\hline
\end{tabular}

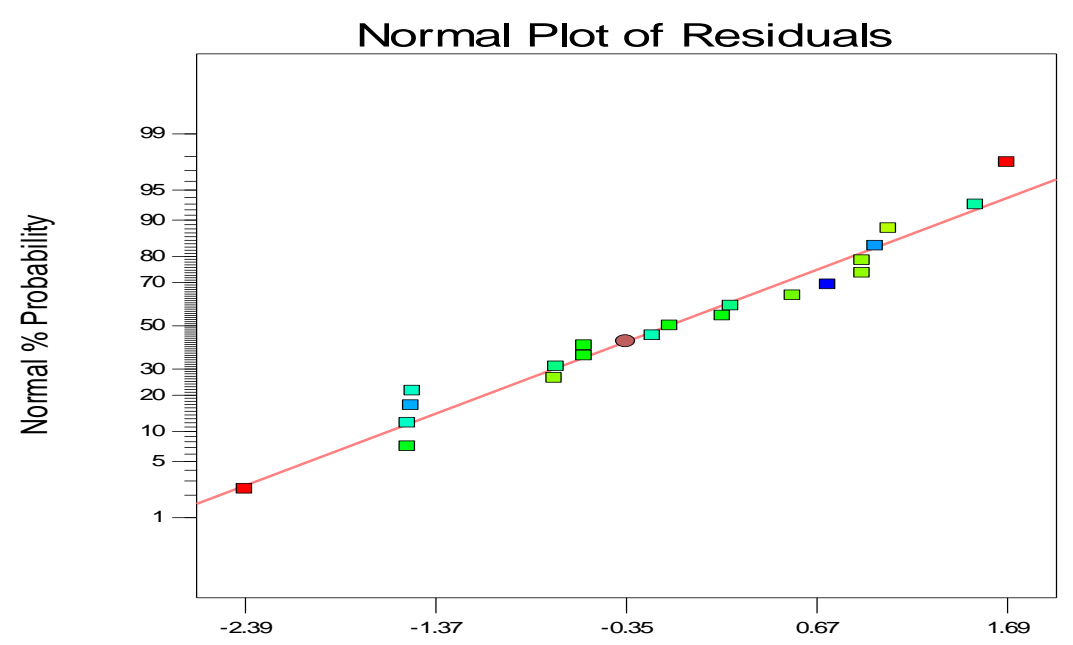

Internally Studentized Residuals

Fig.4.1: Normal plot of residual for surface roughness 
4.2 Effect of Process parameters on Surface Roughness The combined effect of two Process Parameters on Output variables is called interaction effect. For interaction plot, two parameters vary keeping the other two process parameters constant at their central value and observe effect on Output characteristics. This plot is called threedimensional surface plot. So, the significant interactions are shown in figures 4.2-4.7
The interaction effect of pulse on time (Ton) and pulse off time (Toff) on surface roughness (SR) is shown in the figure 4.2. From the figure it is observed that as the value of Ton is increased from 110 to $130 \mu$ s and Toff constant at $30 \mu \mathrm{s}$ the surface roughness value increased from 2.68 to $2.832 \mu \mathrm{m}$. When the value of Toff is increased from 30 to $50 \mu$ s and Ton constant at $110 \mu$ s the surface roughness value decreased from 2.695 to $2.5475 \mu \mathrm{m}$.

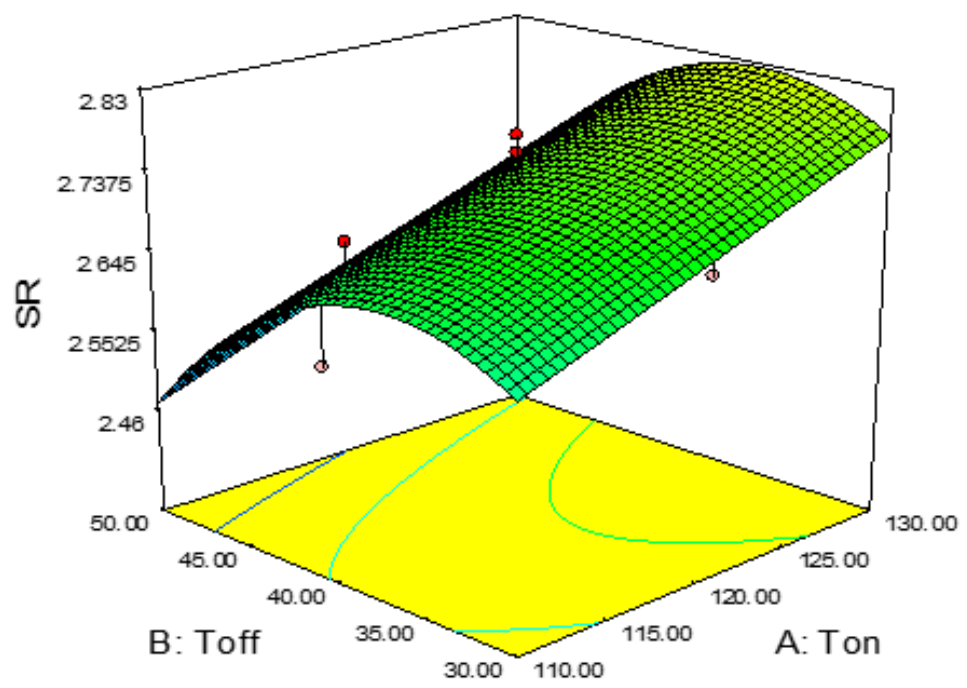

Fig.4.2: Interaction effect of Ton and Toff on surface roughness (SR)

The increase in surface roughness due to increase in pulse on time is due to the fact that a high value of Ton causes longer duration of spark to occur which leads to higher discharge energy which enters deep inside the material. This removes large amounts of material from the work piece producing large hollows. Large hollows are clear indicator of large surface roughness. The decrease in surface roughness due to increase in pulse off time is due to the fact that larger value of pulse off time increases the gap between the two successive sparks which results in impingement of lower discharge energy leading to the removal of fine particles of materials from work piece surface, hollows obtained are light. Hence, lower surface roughness is obtained.

The interaction effect of pulse on time (Ton) and peak current (Ip) on surface roughness (SR) is shown in the figure 4.3. From the figure it is observed that as the value of Ton is increased from 110 to $130 \mu$ s and Ip constant at $80 \mathrm{~A}$ the surface roughness value increased from 2.5475 to $2.90 \mathrm{~m}$. When the value of Ip is increased from 80 to $230 \mathrm{~A}$ and Ton constant at $110 \mu$ s the surface roughness value increased from 2.68 to $2.832 \mu \mathrm{m}$.

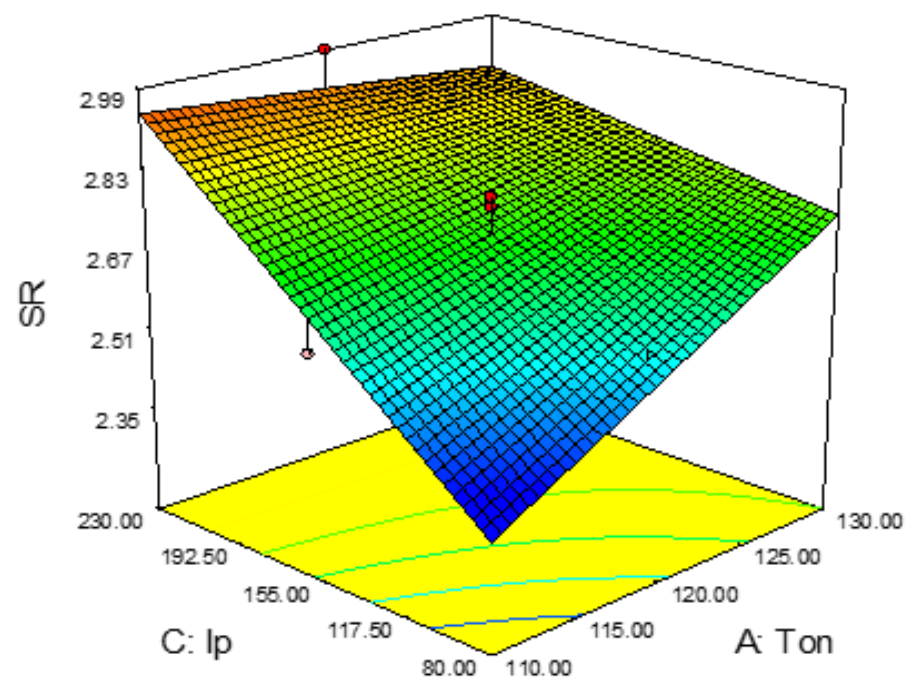

Fig.4.3: Interaction effect of Ton and Ip on surface roughness (SR) 
The increase in surface roughness due to increase in pulse on time is due to the reason mentioned earlier. The increase in surface roughness due to increase in peak current is due to the fact that a larger value of peak current increases the temperature of discharge channel. The energy obtained at large level of Ip has larger heat energy that enter deep inside the material and larger piece of material are removed, which produces larger hollow on work piece surface. Hence, surface roughness increases. The interaction effect of pulse off time (Toff) and peak current (Ip) on surface roughness (SR) is shown in the figure 4.4. From the figure it is observed that as the value of Toff is increased from 30 to $50 \mu$ s and Ip constant at
$80 \mathrm{~A}$ the surface roughness value decreased from 2.695 to $2.5475 \mu \mathrm{sm}$. When the value of Ip is increased from 80 to $230 \mathrm{~A}$ and Toff constant at $30 \mu$ s the surface roughness value increased from 2.68 to $2.832 \mu \mathrm{m}$. The decreased in surface roughness due to increase in pulse off time is due to the reason mentioned earlier. The increase in surface roughness due to increase in peak current is due to the fact that a larger value of peak current increases the temperature of discharge channel. The energy obtained at large level of Ip has larger heat energy that enter deep inside the material and larger piece of material are removed, which produces larger hollow on work piece surface. Hence, surface roughness increases.

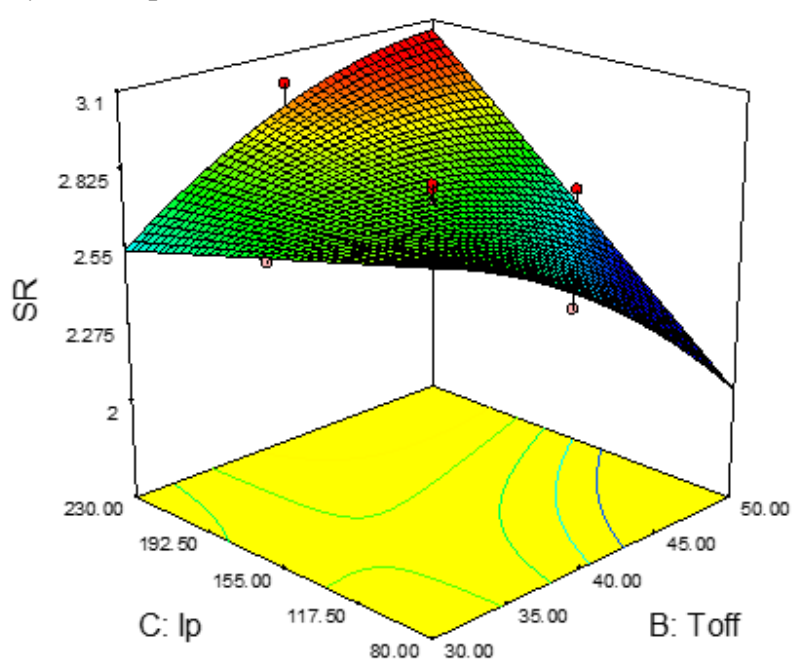

Fig.4.4: Interaction effect of Toff and Ip on surface roughness (SR)

The interaction effect of pulse off time (Toff) and servo voltage (Sv) on surface roughness (SR) is shown in the figure 4.5. From the figure it is observed that as the value of Toff is increased from 30 to $50 \mathrm{~V}$ and $\mathrm{Sv}$ constant at $10 \mathrm{~V}$ the surface roughness value decreased from 2.695 to $2.5475 \mu \mathrm{m}$. When the value of $\mathrm{Sv}$ is increased from 10 to $50 \mathrm{~V}$ and Toff constant at $30 \mu$ s the surface roughness value decreased from 2.695 to $1.5 \mu \mathrm{m}$. The decrease in surface roughness due to increase in pulse off time due to the reasons mentioned earlier. The decrease in surface roughness due to increase in servo voltage is due to the reas on that a high value of servo voltage increases the gap between two successive sparks. Higher the servo voltage longer is the discharge waiting time which results in lower discharge energy, which produces thin hollow on work piece and hence lower surface roughness is obtained.

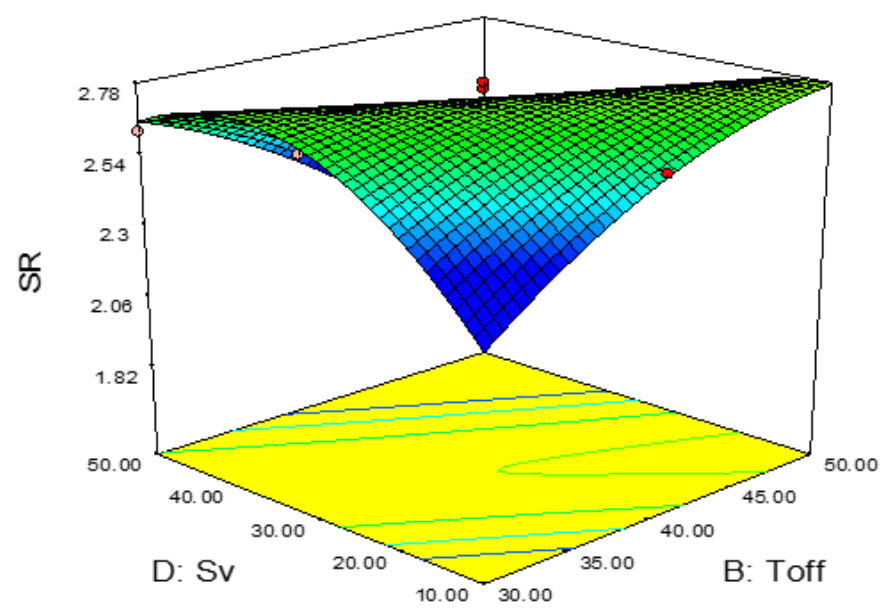

Fig.4.5: Interaction effect of Toff and Sv on surface roughness (SR) 
The interaction effect of pulse on time (Ton) and servo voltage (Sv) on surface roughness (SR) is shown in the figure 4.6. From the figure it is observed that as the value of Ton is increased from 110 to $130 \mathrm{~V}$ and Sv constant at $10 \mathrm{~V}$ the surface roughness value is increased from 2.5495 to $3.0 \mu \mathrm{m}$. When the value of $\mathrm{Sv}$ is increased from 10 to $50 \mathrm{~V}$ and Ton constant at $110 \mu \mathrm{s}$ the surface roughness value decreased from 2.695 to $1.5 \mu \mathrm{m}$. The increase in surface roughness due to increase in pulse on time due to the reasons mentioned earlier. The decrease in surface roughness due to increase in servo voltage is due to the reas on that a high value of servo voltage increases the gap between two successive sparks. Higher the servo voltage longer is the discharge waiting time which results in lower discharge energy, which produces thin hollow on work piece and hence lower surface roughness is obtained.

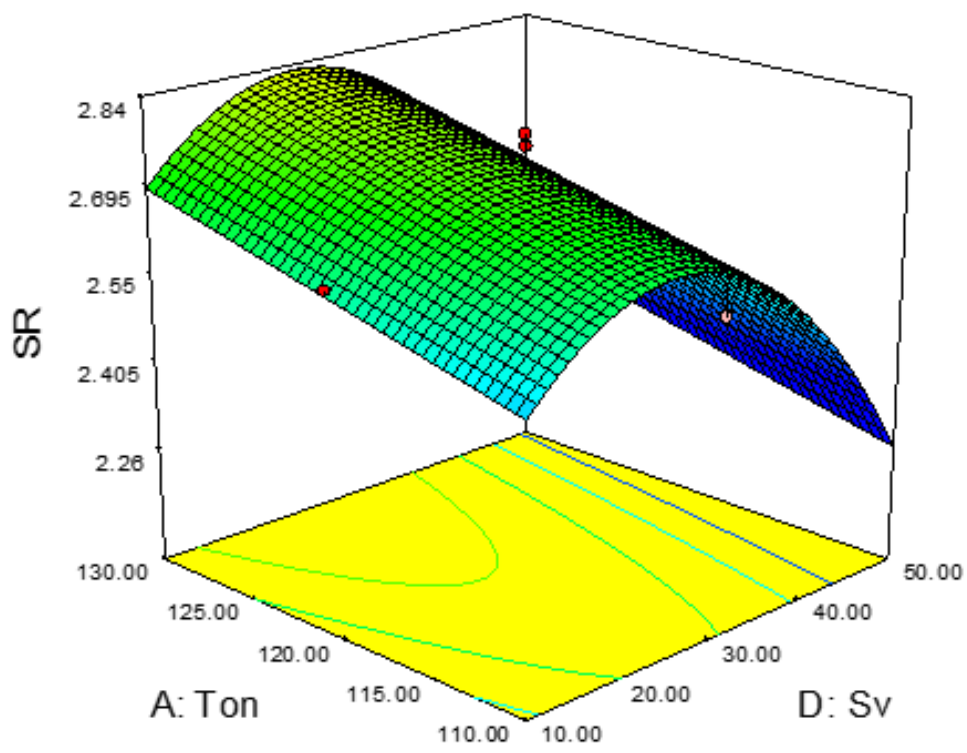

Fig.4.6: Interaction effect of Ton and Sv on surface roughness

The interaction effect of peak current (Ip) and servo voltage (Sv) on surface roughness (SR) is shown in the figure 4.7. From the figure it is observed that as the value of Ip is increased from 80 to $230 \mathrm{~A}$ and $\mathrm{Sv}$ constant at $10 \mathrm{~V}$ the surface roughness value increased from 2.45 to 3.0 $\mu \mathrm{m}$. When the value of $\mathrm{Sv}$ is increased from 10 to $50 \mathrm{~V}$ and Ip constant at $80 \mathrm{~A}$ the surface roughness value decreased from 2.500 to $1.591 \mu \mathrm{m}$. The increase in surface roughness due to increase in peak current and decrease in surface roughness due to increase in servo voltage is due to the reasons mentioned earlier.

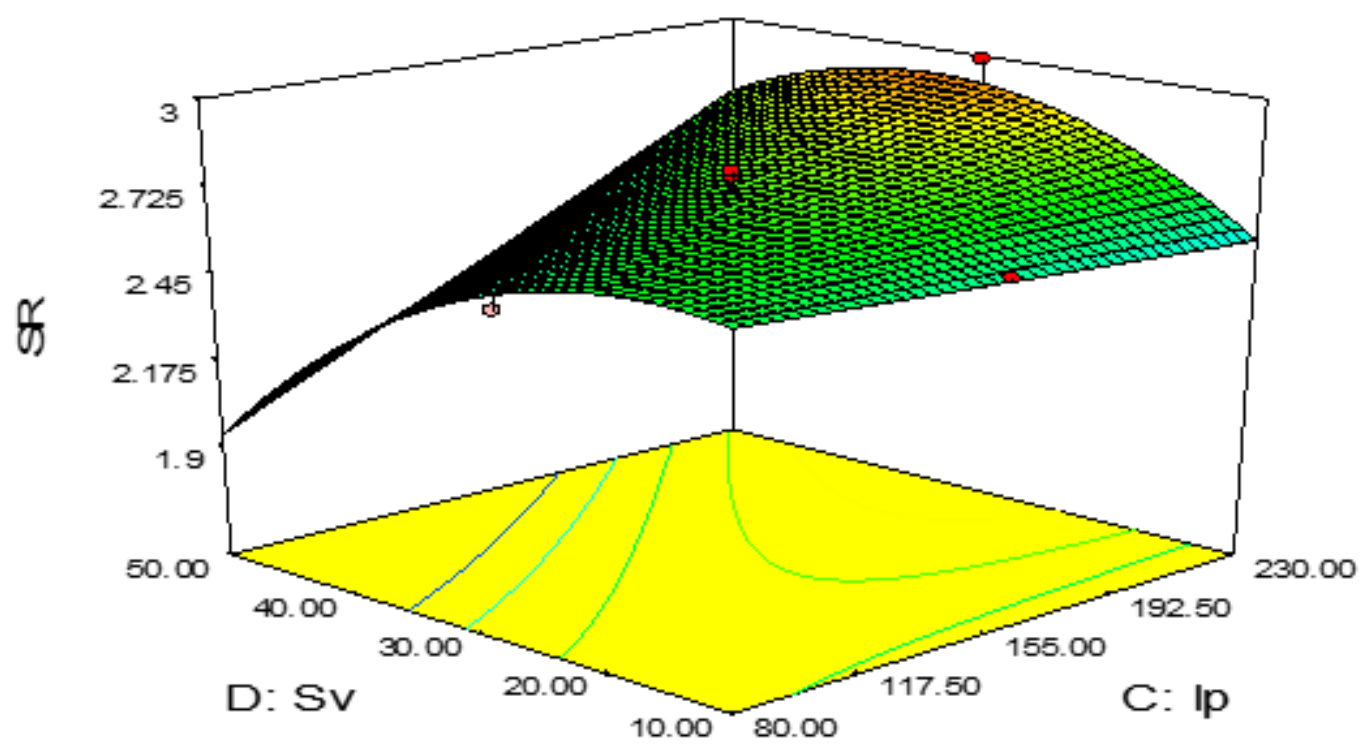

Fig.4.7: Interaction effect of Ip and Sv on surface roughness (SR) 


\section{CONCLUSION}

In this paper the effect of Process Parameters on Surface

Roughness is optimized, it is concluded that:

1. Main effect of pulse on time, pulse off time, peak current and servo voltage and interaction effect of pulse on time and pulse off time, pulse on time and peak current, pulse off time and peak current, pulse on time and servo voltage, pulse off time and servo voltage, peak current and servo voltage and second order of pulse on time, pulse off time, peak current and servo voltage found to be important from the ANOVA of surface roughness

2. Surface Roughness (SR) of the machined surface increased with increase in pulse on time because the discharge energy becomes more controlling with increasing pulse on time, whereas with increase in pulse off time and servo voltage surface finish increases. On increasing the value of peak current, surface roughness of the machined surface increases whereas on decreasing the peak current surface roughness decreases.

3. For Output parameter, the predicted values of the response are in close agreement with experimental results.

\section{REFERENCES}

[1] Ho, K.H., Newman, S.T., Rahimifards, S. and Allen, R.D., 2004, "State of the art in wire electrical discharge machining (WEDM)", International Journal of Machine Tools \& Manufacture, pp. 12471259.

[2] Ramakrishnan, R. and Karunamoorthy, L;2008, "Modeling and multi-response optimization of Inconel 718 on machining of CNC WEDM process", Journal of Materials Processing Technology, pp. 343-349.

[3] P, Jaganathan; Kumar Naveen.T; Dr.R. Siva Subramanian; 2012, "Machining Parameters optimization of WEDM Process using Taguchi method",International Journal of Scientific and Research, Vol.2

[4] Zaman Khan, Noor; Wahid, Mohd. Atif; Singh, Stayover; Sidiquee, Arshad noor; A. khan, Zahid., 2013, "A study of Microhardness on WEDM using Taguchi Method", International Journal of Mechanical and Production Engineering, vol. 1.

[5] Malleswara Rao, S. Sivanaga and Parameswara Rao, Ch. V.S; 2014, "Parametric Evaluation for machining Die steel with WEDM", International Journal of Scientific and Research Publications, vol. 3 (3), pp. 2250-3153.

[6] Chalisgaonkar, Rupesh and Kumar, Jatinder; 2015, "Multi-response optimization and modelling of trim cut WEDMoperation of commercially pure titanium
(CPTi) considering multipleuser's preferences", International Journal of Engineering Science and Technology, pp. 125-134

[7] Saha, Abhijit and Majumder, Himadri; 2016, "Performance Analysis and Optimization in Turning of ASTM 36 through Process Capability Index"Journal of King Saud University Engineering Sciences.

[8] Chaubey, Sujeet Kumar and Jain, Neelesh Kumar; 2017, "State-of-art review of past research on manufacturing of meso and microcylindrical gears", International Journal ofPrecision Engineering Research. 